\title{
Detection of Antibiotic Residue in Raw Bulk Milk in Tiyo and Digelu-Tijo Milk Shades of Arsi Zone, Ethiopia
}

\author{
Mulualem Ambaw* \\ Ethiopian Institute of Agricultural Research, Kulumsa Agricultural Research Center, \\ P.O.Box 489,Kulumsa Ethiopia \\ Samuel Aytenfsu \\ Veterinary Drug and Animal Feed Administration and Control Authority, \\ Addis Ababa, Ethiopia
}

\begin{abstract}
Across-sectional study was conducted from October 30/2017-July 30/2019 to determine antibiotic residues in raw bulk milk in Tiyo and Digelu-Tijo milk shades. Qualitative analysis by using Delvotest SP was conducted to screen antibiotic residues. A total of 125 milk samples were collected for antibiotic screening test. From 125 milk samples screened 12\% 15/125 were positive for antibiotic residues. The prevalence was associated with presence of mastitis, history of use of antibiotics for the treatment of disease in their farms and herd size. The higher prevalence of residues was found in the dairy farms with higher prevalence of mastitis that uses antibiotics commonly for the treatment of mastitis and other disease. The residue occurrence was also higher in dairy farm owners who use antibiotics by themselves for the treatment and prevention of dairy cattle disease than consulting to veterinary for the treatment of the infected animals. The prevalence were statistically significant at $(p<0.05)$. Attention has to be paid to the presence of drug residues in milk by producers, processors and consumers to be aware about the health impact of consumption of antibiotic residue with milk. Finally the use of effective enforcement of milk quality and safety standards is essential to provide the public with safe and wholesome animal product particularly milk and milk products.
\end{abstract}

Keywords: Antibiotic screening, milk shad areas, delvotest SP Assay

DOI: $10.7176 / \mathrm{FSQM} / 107-03$

Publication date: April $30^{\text {th }} 2021$

\section{INTRODUCTION}

Antibiotics have been used in the dairy industry for more than five decades in dairy cattle production to control and prevent disease and to increase milk production or improve feed efficiency (IOM, 1989). Residual antibiotics in milk can seriously affect consumer's health causing allergic reactions and developing resistant strains. Antibiotic contamination in milk can also cause significant economic losses for producers and manufacturers of milk and milk products (Riediker, 2004).Although antimicrobial drugs are useful for treatment of human infections, their occurrence in milk causes adverse public health effects such as drug resistance and hypersensitivity that could be life threatening (Oslon and Sanders, 1975).

The use of antibiotics therapy to treat and prevent udder infections in cows is a key component of mastitis control in many countries. Due to the widespread use of antibiotic for treatment of mastitis in dairy cows, much effort and concerns have been directed towards the proper management and monitoring of antibiotics usage in treatments in order to prevent contamination of raw milk. However, widespread use of antibiotics has created potential residue problems in milk and milk products that are consumed by the general public. Because of the public health significance, milk and milk products contaminated with antibiotics beyond a given residue levels, are considered unfit for human consumption (Hillerton et al., 1999). The good quality of milk must contain no harmful or toxic residues, such as antimicrobial al drugs (Owens et al.,1991). The extra-label use of these antimicrobial, insufficient withdrawal period and lack of records are the most common causes of theses residue in milk, which lead to exceed these residues in milk above the acceptable maximum residue limits (MRLs) (Kaneen and Ahl, 1987). In addition the lack of good veterinary practice and illegal use of veterinary drugs by farmers will increase this problem (Oliver et al., 1990; McEwen et al., 1991).

To detect antibiotic residues in milk different kinds of methods were developed and are applied in laboratory analysis. These consist of screening and chromatographic techniques to detect as many antibiotics as possible. The screening method is generally performed by microbiological, enzymatic and immunological methods. The screening methods were based on various susceptibilities of the bacteria to different antibiotics. The antibiotic residue detection assays that are currently available use different methods and test microorganisms (Mitchell et al., 1998). Microbiological assays for the detection of antibiotic residues utilize bacteria such as Bacillus stearothermophilus because of its high sensitivity to the majority of antibiotics. Both microbiological and chromatographic methods have been described for monitoring antibiotics in milk and animal tissues. Although the microbiological assay techniques have been recommended as official and conventional methods because of their 
simplicity, the bioassay methods lack specificity and provide only semi-quantitative measurements of residues detected and sometimes produce false positives (Kurittu et al.,2000). Therefore, chromatographic techniques, such as TLC, and HPLC, and capillary electrophoresis (CE), have been developed to replace microbiological assays (Cinquina et al.,2004).

In order to safeguard human health, the World Health Organization (WHO) and the Food Agriculture Organization (FAO) and Codex Alimentarius have set standards for acceptable daily intake and maximum residue limits in foods (FAO,1995;CAC,1997). Regulatory limits for antibiotic residues have been imposed on the dairy industry in many countries including European Union Commission Regulation (FDA, 1996; Folly and Machado ,2001;EU,1990).

In Ethiopia, the studies that have been conducted on antibiotics residue levels in milk is limited and as such there are no enough data on the residual levels of these drugs in milk (Desalegneet al., 2014). As a result, policy makers remain largely unaware of the extent of the problem and no quality assurance programs are in place to prevent sales of animal source foods that may contain antimicrobial residues. Therefore, farmers rarely comply with the recommendations and usage is also not monitored by the responsible regulatory authorities. Therefore the objectives of this work were to determine the rate of occurrence (prevalence) of antibiotic residues, by using delvotest SP assay in bulk milk samples and to assess the knowledge, attitude and the level of awareness of dairy farm owners about antibiotic residues in milk.

\section{MATERIALS AND METHODS}

\subsection{Study areas}

This study was conducted in selected milk shade areas of Tiyo and Digelu-Tijo districts Study design

Cross-sectional type of study design were employed .Antibiotic screening by using delvotest SP was conducted. Questionnaire survey was also employed to identify farm management practice.

\subsection{Sampling and sample size}

Simple random sampling technique was employed. Sample size was calculated based expected prevalence of antibiotic residue and desired absolute precision according to Thrusfield,(2005) $\mathrm{N}=1.96 \times \mathrm{xp}_{\exp }\left(1-\mathrm{p}_{\exp }\right)_{/ \mathrm{d} 2}, \mathrm{Where}, \mathrm{n}=$ required sample size; $p_{\exp }=$ expected prevalence $=$ desired absolute precision level at $95 \%$ confidence level and 1.96 is the value of $\mathrm{z}$ at $95 \%$ confidence interval. A total of 162 dairy farms were selected to collect milk samples for antibiotic residue screening.

\subsection{Milk sample collection}

About $50 \mathrm{ml}$ of milk samples from 125 voluntary dairy farms were collected using conical centrifuge tube. The collected milk samples were labeled with permanent marker with full information about the date of collection, location, name of the farm and breeds of the animals. The collected milk samples were transported to the Veterinary Drug and Animal Feed Administration and Control Authority (VDAFACA) in Ethiopia and stored at $20^{\circ} \mathrm{c}$ till analysis

\subsection{Antibiotic Screening test}

Milk samples were collected and screened qualitatively by using Delvotest SP Assay for presence or absence of antibiotics as described by Suhren (1998). It is a microbial inhibition test with Bacillus stearothermophilus as test microorganism. The method combines the principle of agar diffusion tests with a color change of the indicator resulting from the active metabolism of the testing microorganism in the absence of the indicator. The sample examined was put in to a tube filled with agar medium containing B. stearothermophilus var. calidolactis. The bacteria were incubated at $64^{\circ} \mathrm{c}$ from 3 hours'. If the milk contains residues of antibiotics no growth of the bacteria occur within the incubation period, the color of the indicator remains purple no color change at all. On the other hand if the tested milk sample is free of antibiotic residues the tested strain is growing, causes that the color of the indicator (bromcresol red) will change from purple to yellow.

\subsection{Data management and analysis}

The collected data were double entered in Micro-Soft computer program Excel Version 6.0 and analyzed using SPSS version 20. Descriptive statistics were used to the result of milk yield and quality parameters. Percentage and frequency was also used to describe the prevalence of antibiotics residues in raw milk. Chi-square test was also used to determine the association between the dependent and risk factors for antibiotic residues in raw milk. Tables were used to present the results. 


\section{RESULT AND DISCUSSION}

\subsection{Delvotest SP analysis result}

Out of 125 milk samples tested $15(12 \%)$ were positive to antibiotic residue in the study dairy farms with rapid antibiotic screening test by using delvotest SP twine sensor kit. All the positive milk samples were from dairy farms located in Tiyo and Sagure districts. The prevalence of antibiotic residues were higher $8 \%$ in Tiyo than Sagure 5/55 (4\%). The residue prevalence of our result was similar with Desalegn et al. (2014) who reported the prevalence of the antibiotic residues of $12 \%$ conducted in Nazareth dairy farms, in Ethiopia and higher than other research reports and Ergin Kaya and Filazi (2010) conducted in in Ankara- Turkey. Another study conducted by Sudershan and Bhat,(1998) and McEwen et al.(1992) revealed in India indicated 9\% and 9.4\% prevalence of residues of antibiotic respectively which are both comparable with the results of this study. Sternesjö and Johnsson, (1998) in Sweden reported 0.08\%-0.26\% positive for antibiotic residues which were much lower than the present study. On the other hand the higher prevalence of antibiotics residue 21\%,23\% and 30\% were reported by Seymour et al. (1988), Mohamed et al (2020) and Mortez et al (2016) respectively. This variation in the level of contamination of milk with antibiotic residues could be presence or absence of legislation and regulations with regards to the use of antimicrobials in each countries, differences in laboratory test methods and skills, variation in farm management system in different regions, sample size and cultural practices (Kaya and Filazi, 2010). In addition high disease prevalence of mastitis, widespread use and indiscriminate application of antibiotics in the livestock production particularly in the dairy industry could result the presence of residues of antimicrobials in raw milk. Since milk is complete food for infants and it is also perishable and can easily be contaminated with biological and chemical agents. Consumption of milk contaminated with antibiotic residues above Maximum residue limit (MRL) level set by Codex and EU can affect the health of the public directly and indirectly. The common antibiotics frequently used in the dairy sector so far identified are beta lactam and Oxy tetracycline antibiotic groups. Based on dairy producers and veterinary professional's response pen strip from beta lactam and Oxyttc from Oxy Tetracycline groups were the most frequently used antibiotics in the study areas.

\subsection{Factors affecting antibiotic residues in the study areas}

Disease prevalence, breeds of the dairy cows, management of dairy cows, quality of feed and water, source of water, west management, and use of antibiotics in the dairy farm, veterinary service and record keeping are some of the risk factors. The majority $98.4 \%$ of the breed composition of the dairy farms contain cross breeds and the remaining $1.6 \%$ both cross and local reeds. The prevalence of mastitis in cross breed cows is very high compared with local breeds. The prevalence of mastitis in the study dairy farms at least one dairy cows infected were $44 \%$. Regarding animal prevalence, $34.4 \%$ of the dairy farms in the study areas, two and more than two dairy cows were infected with mastitis in each farm and the remaining $65.6 \%$ farms, only one animal were infected with mastitis. The result was compare able with Workineh et al.(2000) 25.1\%, Desalegne et al.(2014) 38.2\% in Addis Ababa and Debrezeit and Nazareth dairy farms respectively. The use of antibiotics (penicillin G) for the treatment of mastitis was common in the study dairy farms which can be one of the predisposing factors for residues in milk. Similarly Owens et al., (1991) reported the continuous use of antibiotics for the treatment and control of mastitis can be one of the predisposing factors. Similarly Andrea et al (2016) reported (Pencilin G) as frequently used antibiotics for the treatment of mastitis in Italy. Mastitis prevalence and awareness of producer farmers are described under (Table1).

Knowledge, perception and awareness level of producers on antibiotic use, withdrawal period and human health impacts of consumption of milk contaminated with antibiotics are the major factors for residue occurrence in milk in the study farms. It is because only $13 \%$ of the producer farmers were aware of about antibiotic residue in milk which can contribute not to respect withdrawal period of antibiotics. Similarly milk production at the time of treatment, type and amount of antibiotic used, types of vehicle used in antibiotic formulation and disease state of the animals were reported by Mercer, et al.(1970) as the major risk factors for the presence of antibiotic residues in milk. In addition the extra-label use of antibiotics without respecting the withdrawal period, lack of records, lack of good veterinary practice and illegal use of veterinary drugs by farmers are also reported as most common causes of residue in milk, which lead to exceed these residues in milk above the acceptable maximum residue limits (MRLs) (Mercer, et al., 1970)

Based on the analysis result the antibiotic residue is high in dairy farms commonly using antibiotics for the treatment of the dairy cows by them-selves. The prevalence is statistically significant at $(\mathrm{p}<0.05)$ see $($ Table 2$)$ below. Antibiotic residues could be detected if the producers use milk from treated dairy cows during treatment and before withdrawal period of antibiotics is terminated. High prevalence of mastitis in the farm with no good veterinary service, poor knowledge of producers on veterinary record, and importance and effect of antibiotics use could be some of the predisposing factors for residues development aggravated with absence of functional legislation and regulation on the use of antibiotics and milk quality and safety standards in Ethiopia. Prevalence of detection of antibiotics in raw milk was higher $75 \%$ in dairy cows treated by the producers themselves than dairy cows treated by veterinary professionals only $5 \%$ and both veterinary professionals and owners themselves 
$18.4 \%$ respectively. Residue detection was common and high in the dairy farms with the history of mastitis prevalence. The highest $18.2 \%$ of the dairy farms with mastitis positive farms were positive for antibiotic residues whereas the lower prevalence (7.7\%) 5/65 of residues was detected from mastitis negative farms.

Dairy cow ownership and milk yield per day are described under (Table3). The mean, minimum and maximum dairy cows ownership in the study areas were 4, 1 and 8 respectively. From those dairy cows on average 2 of them were lactating with minimum and maximum of 1 and 5 lactating cows. On average 7 litters of milk per day were obtained in the study dairy farms with minimum and maximum of 3 and 17 litters. The prevalence of antibiotic detection was significant at $90 \%$ confidence level. Antibiotic residues were higher in farms with large herd size than small herd size. It could be associated with disease prevalence and use of antibiotics dependent on herd size.

\section{CONCLUSION AND RECOMMENDATIONS}

Mastitis and other reproductive diseases and low awareness level of producers on antibiotic use and impact of residues on public health ware the major factors for the use of antibiotics and residue occurrence in the study farms. Even though dairy farmers practice unlimited use of antimicrobials for the treatment, of infectious diseases and as a prophylactic use, aggravated with very low awareness level about drug withdrawal period, antibiotic residue prevalence was moderate. If the dairy farmers assisted and advised by veterinary professionals during treatment of diseased dairy cows about the drug residues and withdrawal periods, human health impact of consuming of milk with antibiotic residues and record keeping during treatment; the prevalence of antibiotic residues will become decreasing to the lower level. Attention has to be paid to the presence of drug residues in milk. In addition dairy producers' farmers, milk collectors and consumers should be aware about the health impact of consumption of antibiotic residue with milk. Finally the use of effective enforcement of milk quality and safety standards is essential to provide the public with safe and wholesome animal product particularly milk and milk products.

\section{ACKNOWLEDGEMENT}

Ethiopian Institute of Agricultural Research Institute, Kulumsa Agricultural Research Center is acknowledged for financing the research work. My grate appreciation goes to Veterinary experts in respective study districts and dairy farmers for their cooperation during data and sample collection. Finally veterinary experts in Veterinary Drug and Animal Feed Administration and Control Authority are also acknowledged for their support during laboratory analysis for antibiotic residue screening.

\section{References}

Cinquina, AL., Longo, F., Anastasi, G., Giannetti , L., Cozzani ,R. ( 2003) .Validation of a high- performance liquid chromatography method for the determination of oxytetracycline, tetracycline, chlortetracycline and doxycycline in bovine milk and muscle. Journal of Chromatography A 987, 227-233.

Codex, Alimentarius (CAC). (1997) . General requirements (food hygiene), 21- 30, Rome.Codex Alimentarius Commission. Vol. 1 B.

Desalegne, A., Kelay, Belihu., and Girma, Zewde. (2014). Detection and determination of oxytetracycline and penicillin $\mathrm{G}$ residue levels in bulk milk of cows in Nazareth dairy farms. Ethiop. Vet. Journal 18 (1), 1-15.

European Union Commission Regulation (EU) ( 1990) .No. 508/1999. 1999 In. Official Journal f the European Community L 60/16 of 4/03/99.

Folly and Machado, S . (2001). Antibiotic residues determination, using microbial inhibition, protein binding and immunoassays methods, in pasteurized milk commercialized in the northern region of Rio de Janeiro State, Brazil. Cienc. Rural 31,95-98.

Food and Agriculture Organization (FAO)/World Health Organization (WHO) (1995) . Application of risk analysis to food standards issues. Report of the Joint FAO/WHO expert consultation. Geneva, Switzerland, WHO/FNU/FOS/95.3, Pp13-17.

Food and Drug Administration (FDA) U.S.A. (1996) .Evaluation and use of milk. Antimicrobial drug screening tests report. Centre for food safety and applied nutrition. FDA prime connection. Rockville, M. D., 20855.Great Britain Pp 182-198.

Hillerton, J .E., Halley, B. I., Neaves, P. and Rose, M. D .(1999) . Detection of antimicrobial substances in individual cow and quarter milk samples using Delvotest microbial inhibitor tests. J.Dairy Sci 82, 704-711.

Institute of Medicine (IOM) (1989). Human health risks with sub-therapeutic use of penicillin or tetracyclines in animal feed. Committee on human health risk assessment on using subtherapeutic antibiotics in animal feeds. National Academy Press, Washington, DC.

Kaneen, J.B., and Ahl, A.S .(1987) .Drug residues in dairy cattle industry: Epidemiological evaluation of factors influencing their occurrence. J. Dairy Sci 70, 2176-2180.

Kaya, E.S and Filazi, A .(2010) .Determination of antibiotic residue in milk samples. Research Article 16, 31 35. 
Kurittu, J., Lo“nnberg, S., Virta, M., \& Karp, M. (2000) . Qualitative detection of tetracycline residues in milk with a luminescence based microbial method: The effects of milk composition and assay performance in relation to an immunoassay and a microbial inhibition assay. J. F. Protection 63, 953-957.

McEwen, S. A., Black, W .D and Meek, A .H. (1992). Antibiotic residues (bacterial inhibitory substances) in the milk of cows treated under label and extra label conditions. Can Vet J 33(8), $527-34$.

McEwen, S. A., Meek, A .H., and Black, W .D. ( 1991) . A dairy farm survey of antibiotic treatment practices, residue control methods and associations with inhibitors in milk. J. Food Prot 5, 44-54.

Mercer, H. D., Geleta, J. N., and Wright, W. W. (1970). Milk out rates for antibiotics in intramammary infusion products used in the treatment of bovine mastitis: Relationship of somatic cell counts of milk production levels and drug vehicle. Am. J. Vet. Res 31,1549-1560

Mitchell, J. M., Griffiths, M.W., McEwen, W .B \& Yee, A. J. (1998).Antimicrobial drug residues in milk and meat: causes, concerns, prevalence, regulations, tests and test performance. J. Food Prot 61,742-756.

Oliver, S.P., Maki, J .L., Dowlen, H. H. (1990) ."Antibiotic residues in milk following antimicrobial therapy during lactation”. Journal of Food Protection 53, 693-696.

Oslon, J.C., Sanders, A.C .(1975) . Penicillin in milk and milk products. Some regulatory and public health considerations. J Milk Food Techno 38, 630-633.

Owens, W.E., Nickerson, S.C., Washburn, P.J. and Ray, C.H .(1991). Efficacy of a cephapirin dry cow product for treatment of experimentally induced Staphylococcus aureus mastitis in heifers.J. Dairy Sci 74,3376-3382.

Riediker, S., Rytz, A .and Richard ,S .(2004) . Cold-temperature stability of five-lactam antibiotics in bovine milk and milk extracts prepared for liquid chromatography- electrospray ionization tandem mass spectrometry analysis. Journal of Chromatography a1054, 359-363.

Seymour, E.H., Jones, G.M., McGilliard, M.L. (1988).Persistence of residues in milk following antibiotic treatment of dairy cattle. J Dairy Science 71 (8), 2292-2296.

Sternesjo, A .and Johnsson, G. (1998).A novel rapid enzyme immunoassay for detection of $\beta$ lactam residues in farm raw milk. J. Food Prot 61, 808-811.

Sudershan, V. and Bhat, R .(1998).A survey on veterinary drug use and residues in milk in Hyderabad. Food Addit. Contam. 12, 645-650.

Suhren, G., and Beukers, R. (1998) . Delvotest SP for detection of cloxacillin and sulfamethoxazole in milk. IDF interlaboratory study. J. AOAC Int 81, 978-990.

Thrusfield ,M. (2005) .Veterinary epidemiology. 3rd ed. Blackwell Science Ltd., Oxford,

Workineh S, Bayleyegne M, Mekonnen H and Potgieter L N D (2000). Prevalence and etiology of mastitis in cow from two major Ethiopian dairies.Trop.Anim. Hlth Production.34,19 25.

Mohamed, Abdelrahman., Mohamed et al. (2020) Antibiotic residue in raw milk collected from dairy farms and markets in Benadir, Somalia. PAMJ - One Health 2(19). 10.11604/pamj-oh.2020.2.19.24814

Kaya, S.E., Filazi ,A.(2010). Determination of antibiotic residues in milk samples. Kafkas Univ Vet Fak Derg 16, S31-5. https://doi.org/10.4081/ijas.2013.e

Mortez, Mohammadzadeh., Moghadam, Mostafa., Amiri, Hamed., Ramezani, Awal.,Riabi, and Hamid, R.A.Riabi.2016. Evaluation of Antibiotic Residues in Pasteurized and Raw Milk Distributed in the South of Khorasan-e Razavi Province, Iran. J Clinical Diagnostic Research.10(12): FC31-FC35. doi: 10.7860/JCDR/2016/21034.9034. 
Table 1.factors affecting antibiotic residues in raw milk

\begin{tabular}{|c|c|c|c|}
\hline Category & & No & Present $\%$ \\
\hline \multirow[t]{2}{*}{ Breeds } & Cross & 123 & $98.4 \%$ \\
\hline & Both & 2 & $1.6 \%$ \\
\hline \multirow[t]{2}{*}{ farm Ventilation } & Present & 124 & $99.2 \%$ \\
\hline & Absent & 1 & $0.8 \%$ \\
\hline \multirow[t]{2}{*}{ Drainage } & Present & 120 & $96 \%$ \\
\hline & Absent & 5 & $4 \%$ \\
\hline \multirow[t]{2}{*}{ Floor type of the dairy farm } & Concrete & 109 & $87.2 \%$ \\
\hline & Mud & 16 & $12.8 \%$ \\
\hline \multirow[t]{3}{*}{ Feeding of dairy cows } & Concentrate & 2 & $1.6 \%$ \\
\hline & Raphage & 1 & $0.8 \%$ \\
\hline & Both concentrate and raphage & 122 & $97.6 \%$ \\
\hline \multirow[t]{2}{*}{ Quality of feed } & Not tested & 125 & $100 \%$ \\
\hline & Tested & 0 & 0 \\
\hline \multirow[t]{5}{*}{ Water source of cows } & River & 11 & 8.8 \\
\hline & Underground & 4 & 3.2 \\
\hline & Tap water & 76 & 60.8 \\
\hline & Underground and tap water & 23 & 18.4 \\
\hline & River and tap water & 11 & 8.8 \\
\hline \multirow[t]{3}{*}{ Quality of water for dairy cows } & Clean & 104 & 83.2 \\
\hline & Not clean & 2 & 1.6 \\
\hline & Unknown & 19 & 15.2 \\
\hline \multirow[t]{2}{*}{ West management } & Present & 121 & 96.8 \\
\hline & Absent & 4 & 3.2 \\
\hline \multirow[t]{2}{*}{ Use of medicinal plant for treatment } & Present & 56 & 44.8 \\
\hline & Absent & 69 & 55.2 \\
\hline \multirow{2}{*}{ Use of antibiotics in the dairy farm } & Common & 102 & 81.6 \\
\hline & Rare & 23 & 18.4 \\
\hline \multirow[t]{3}{*}{ Treatment of dairy cows } & Veterinary profession & 63 & 50.4 \\
\hline & Self-medication & 4 & 3.2 \\
\hline & Both vets and self-treatment & 58 & 46.4 \\
\hline \multirow[t]{2}{*}{ Milk yield record keeping } & Present & 123 & 98.4 \\
\hline & Absent & 2 & 1.6 \\
\hline \multirow[t]{2}{*}{ Milk physical characteristics by color } & Normal & 124 & 99.2 \\
\hline & Abnormal & 1 & 0.8 \\
\hline \multirow[t]{2}{*}{ Milk physical characteristics by Oder } & Normal & 122 & 97.6 \\
\hline & Abnormal & 3 & 2.4 \\
\hline \multirow[t]{2}{*}{ Debris in milk } & Present & 19 & 15.2 \\
\hline & Absent & 106 & 84.8 \\
\hline White flank in milk & Absent & 125 & 100 \\
\hline Particles in milk & Absent & 125 & 100 \\
\hline Butter granuls in milk & Absent & 125 & 100 \\
\hline \multirow[t]{2}{*}{ Mastitis } & Present & 55 & $44 \%$ \\
\hline & Absent & 70 & $56 \%$ \\
\hline \multirow[t]{2}{*}{ Knowledge on antibiotic residues } & Yes & 16 & $12.8 \%$ \\
\hline & No & 109 & $87.2 \%$ \\
\hline
\end{tabular}


Table 2.association between antibiotic residue results against different risk factors

Risk factors

Who give treatment for dairy cows

veterinary professionals

self-medication

Both veterinary profession and selfmedication

Total antibiotic screening result Positive

Antibiotic use

Common

Rare

Total

Presence mastitis in the farm

Yes

No

Total

Herd size

1-4

$>4$

Total
Negative

$\begin{array}{rr}3 & 60 \\ 3 & 1 \\ 9 & 49 \\ & \\ 15 & 110\end{array}$

60

10

993

$6 \quad 17$

$10 \quad 45$

$5 \quad 65$

$15 \quad 70$

$\begin{array}{ll}7 & 75\end{array}$

$8 \quad 35$

$15 \quad 110$

17

70

$15 \quad 110$

$\mathbf{X}^{2} \quad$ p-value

18.8

0.001

5.3

0.02

0

3.6

0.054

2.7

0.1

Table 3.Avarage dairy cows ownership milk yield in the study areas.

\begin{tabular}{llrrrr}
\hline \multicolumn{7}{c}{ Descriptive Statistics } & & \\
\hline Category & $\mathrm{N}$ & Minimum & Maximum & Mean & Std. Deviation \\
\hline total numbers of dairy animals & 125 & 1.0 & 8.0 & 3.7 & 1.6 \\
total number of lactating cows & 125 & 1.0 & 5.0 & 2.0 & 1.1 \\
total milk per day in the farm & 125 & 3.0 & 17.0 & 7.0 & 3.8 \\
number of non-milking cows & 125 & .0 & 5.0 & 1.6 & 1.1 \\
\hline
\end{tabular}

